\title{
Investigation of Neutron in Linear Accelerator at Dong Nai Genegal Hospital by Using the Neutron Activation Method
}

\author{
Nguyen Van Hai ${ }^{{ }^{*}}$, Nguyen Van Hung ${ }^{2}$, Nguyen Van $\mathrm{Hoa}^{3}$ and Dao Thi Kim $\mathrm{Nhung}^{3}$ \\ ${ }^{1}$ Dalat Vocational Training College, Vietnam \\ ${ }^{2}$ Nuclear research Institute, Vietnam \\ ${ }^{3}$ Health Center of Lac Duong, Vietnam
}

"Corresponding author: Nguyen Van Hai, Dalat Vocational Training College, 01 Hoang Van Thu Street, Warn 4, Dalat City, Lam Dong Province, Vietnam, Tel: +84913063277; E-mail: haiitdl@gmail.com

Received date: Mar 10, 2015, Accepted date: Apr 15, 2015, Publication date: Apr 20, 2015

Copyright: (C) 2015 Hai NV, et al. This is an open-access article distributed under the terms of the Creative Commons Attribution License, which permits unrestricted use, distribution, and reproduction in any medium, provided the original author and source are credited.

\begin{abstract}
The principles of linear accelerator are: the accelerator emits two types of radiation that are photon and electron. However, when we were doing the research and working on it, we have found that neutrons have emitted from the accelerator.

This paper aims to show some results of measuring neutrons from a linear accelerator at Dong Nai General Hospital. The results of this experiment will be used to ensure the safety of radiation as well as the background for the incoming research.
\end{abstract}

Keywords: Linac; Neutron activation; Radiation therapy

\section{Introduction}

Based on the theory, photons with energy which is greater than $6 \mathrm{MV}$ is able to generate a reaction $(\gamma, \mathrm{n})$. This reaction depends on the material of target, it will create a beam of neutrons with considerable intensity. In order to measure this beam of neutrons, we have used a ALOKA dose meter.

However, the result hasn't been very reliable because the secondary radiations have taken part in the measuring process and this dose meter can measure the other radiations. Therefore, we have used the neutron activation method to measure and calculate the dose rate of neutron from Dong Nai General Hospital.

\section{The Theory}

When neutron with high energy- interacts with a nucleus target, two main processes that are elastic scattering and neutron capture reaction can occur.

In case neutron capture happens, a compound nuclear is generated with the stimulating energy equal to the combined energy between the neutron and the nuclear and kinetic energy of the incident neutron.

The compound energy exists in the simulating state during $10-{ }^{14} \mathrm{~S}$ then it decays to basis state or ISOME state by radiating prompt gamma ray and forms radioactive nucleus with mass number equal to $\mathrm{A}+1$. Most of the nucleus are unstable and decay to a new nuclear by emitting beta and gamma ray called delayed gamma ray.

The process of activation by neutron capture reaction is illustrated in Figure 1.

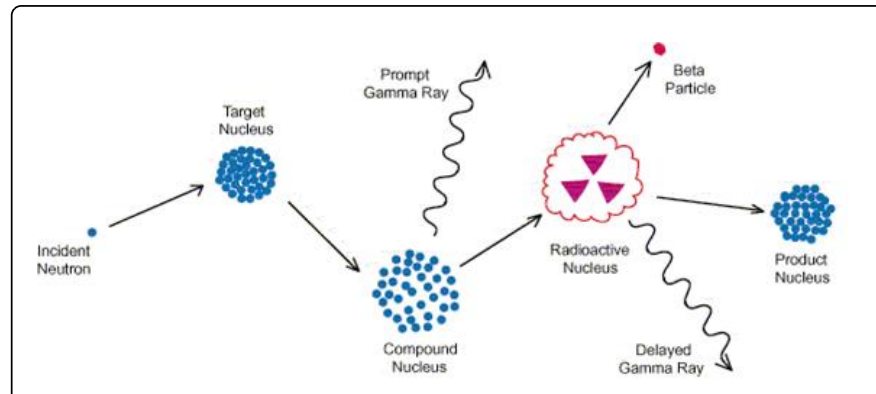

Figure 1: The process of activation by radiation neutron capture reaction.

By using samples of standard target nucleus is exactly known as element content, quantity of samples, the common of isotope, geometry of samples, cross section of radiation-capture and measuring delayed gamma spectrometry from radioactive nucleus with multichannel spectrometer-HPGe. The information on neutron flux density at the position of the samples will be determined accurately [1-4].

\section{Carrying Out the Experiment}

To obtain the accurate and reliable results, it is necessary to limit the error sources which can contribute to the measurement results. Therefore, the samples are used in experiments must meet certain requirements as follows:

- The samples must have high purity.

- The samples must have stable chemical composition, it is best to use metal.

- Samples must have thin thickness in order that the self-shielding effect is negligible. The sample is considered thin is: $\left(\Sigma_{\mathrm{a}}+\Sigma_{\mathrm{s}}\right) \cdot \mathrm{d}<<1$ 
Citation: Hai NV, Hung NV, Hoa NV, Nhung DTK (2015) Investigation of Neutron in Linear Accelerator at Dong Nai Genegal Hospital by Using the Neutron Activation Method. J Nucl Med Radiat Ther 6: 222. doi:10.4172/2155-9619.1000222

Page 2 of 4

in which $\Sigma_{\mathrm{a}}+\sum_{\mathrm{s}}$ is called macro cross section absorption and macro scattering for neutrons, $\left(\Sigma_{\mathrm{a}}=\mathrm{N} \sigma_{\mathrm{a}}\right), \mathrm{N}$ : number of nuclears in $1 \mathrm{~cm}^{3}$, $\sigma_{\mathrm{a}}$ micro cross section absorption and scattering for neutrons, we defined $\Sigma_{\mathrm{s}}$ similarly.

- Resonance energy and energy thresholds in the different reactions should have good distance.

- Nuclear product obtained after activation with the following characters:

+suitable half-life.

+A known simple decay scheme

+emitting gamma radiation without interference from radiation background of surroundings.

From the above criteria, we choose gold $\left({ }^{197} \mathrm{Au}\right)$ as a sample with diameter $1.27 \mathrm{~mm}, 0.05 \mathrm{~mm}$ thick, for these experiments. The image of the gold samples is illustrated as the Figure 2. The characteristicsof gold is presented in Table 1. In that table we show characterristecs of ${ }^{197} \mathrm{Au}$, and ${ }^{198} \mathrm{Au}$ (Radioactive nuclues) [4-6].

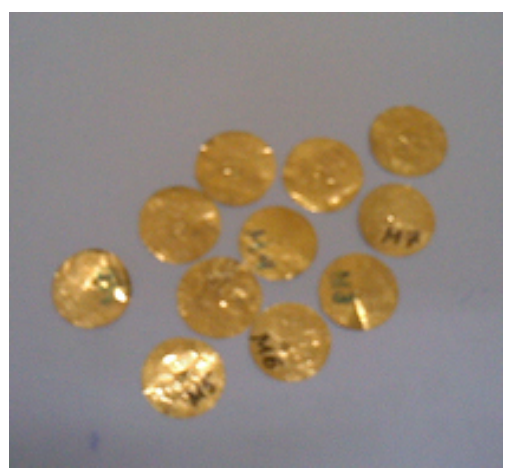

Figure 2: Samples ${ }^{197} \mathrm{Au}$ used in the experiments.

\begin{tabular}{|l|l|l|l|l|l|l|}
\hline Nuclear & $\begin{array}{l}\text { Popularity } \\
(\mathbf{\theta}(\%)\end{array}$ & $\mathbf{\sigma}_{\mathrm{a}}(\mathrm{barn})$ & $\begin{array}{l}\text { Product of } \\
\text { activation }\end{array}$ & $\mathbf{T}_{1 / 2}$ & $\mathbf{E}_{\mathrm{\gamma}}(\mathbf{k e V})$ & $\mathbf{Y}(\%)$ \\
\hline $197 \mathrm{Au}$ & 100 & 98.8 & $198 \mathrm{Au}$ & $\begin{array}{l}2,69 \\
5\end{array}$ & 411 & 95 \\
\hline
\end{tabular}

Table 1: Characteristics of samples ${ }^{197} \mathrm{Au}$.

The process of sample preparation: Cleaning by alcohol $\rightarrow$ drying $\rightarrow$ weighing to define the mass with electronic scale, the accuracy is 0.0001 gram. The sample is put into a container. Then it will be taken to the Hospital in order to be attached to the positions as presented in Figure 3.

The distance from the Hospital to the location with the delayed gamma spectrometer is $200 \mathrm{~km}$ and the time of moving is 8 hours. On the other hand, the Hospital only can use radioactive therapy for 2 hours/ day (depending on the patient) (Table 2). Therefore, we only carry out the process of neutron activation during 2 hours, but the time emit only 20 minutes. After that, we carry out the measuring process, we have done to bring the sample to analyze, calculate flux of delay by Gamma spectrometer in Figure 4 software gamma vision at Figure 5 [5].
The most important aim in this paper is investigation neutron inside treament room, therefore the result just only care about dose rate of neutron, don't discriminate between neutrons.

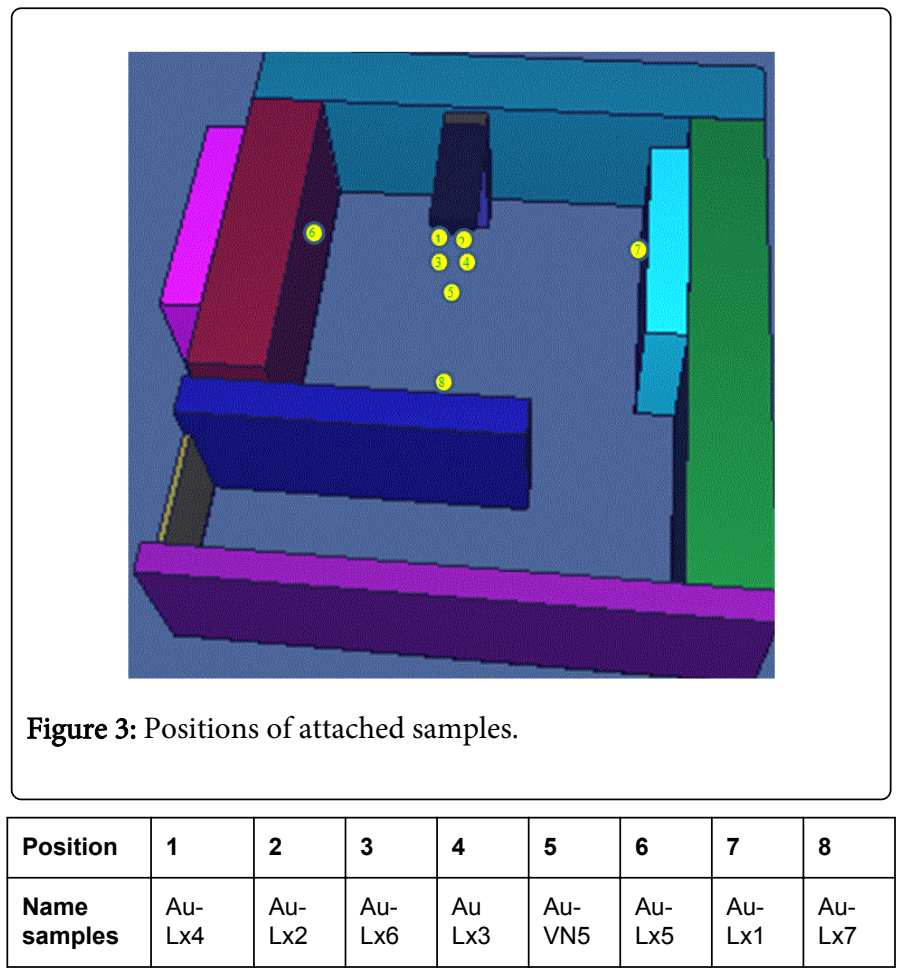

Table 2: The position corresponding to the activated sample.

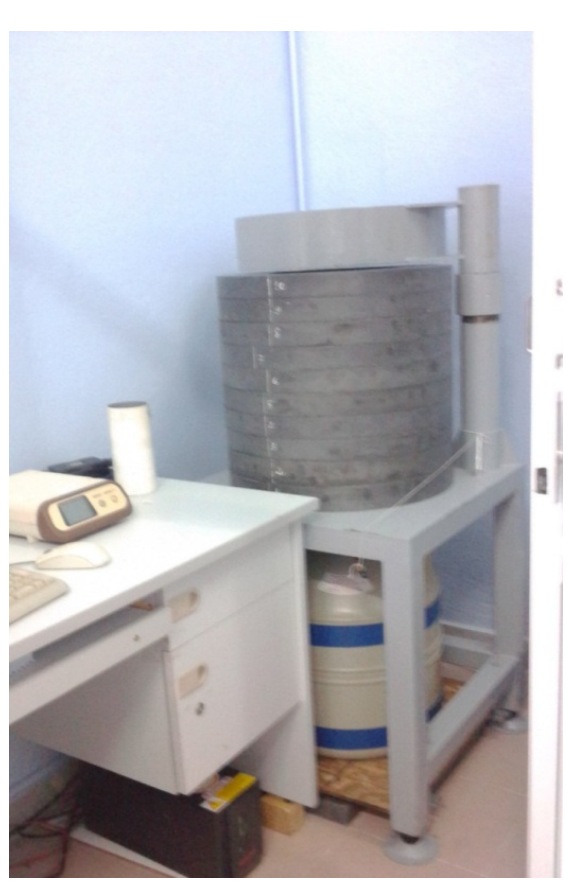

Figure 4: Spectrometer used in experiments. 
Citation: Hai NV, Hung NV, Hoa NV, Nhung DTK (2015) Investigation of Neutron in Linear Accelerator at Dong Nai Genegal Hospital by Using the Neutron Activation Method. J Nucl Med Radiat Ther 6: 222. doi:10.4172/2155-9619.1000222

Page 3 of 4

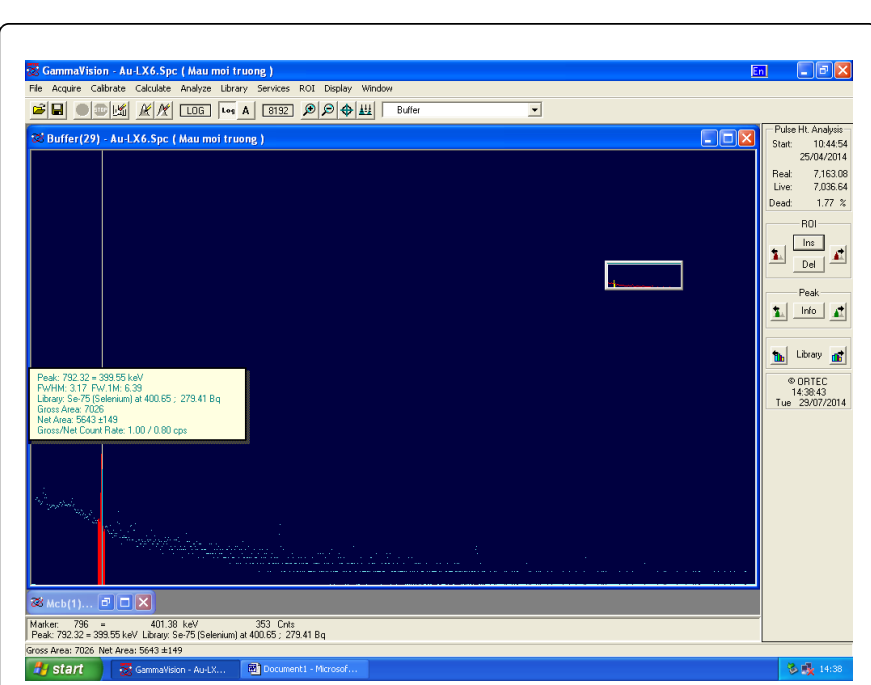

Figure 5: Results of processing with delay gamma by Gamma Vision software.

\section{Result and Discussion}

Results of the analysis, process, calculate. We obtained neutron flux at the positions in the radiation therapy room (Figure 4). These results demonstrate the generation of great amounts of neutron radiation therapy room (Table 3 ).

To determine dose rate of neutron from flux of neutron: Dose rate of neutron can determine from results calculation flux by using International standard about exchange coefficient from flux to dose rate (Table 4). Two populer standards using now are: 10CFR (US Nuclear Regulatory Commission) and another one is NCRP (National Council on Radiation Protection and Measurement) (Figure 6) [4,6].

\begin{tabular}{|l|l|l|}
\hline \multirow{2}{*}{ Neutron $(\mathrm{eV})$} & \multicolumn{2}{|l|}{ Neutron Flux $\left(\mathbf{n} / \mathrm{cm}^{2} \mathbf{s}\right)$ per $\mathbf{~ m R e m} / \mathbf{h}$} \\
\cline { 2 - 3 } & $\mathbf{1 0 C F R} \mathbf{2 0}$ & NCRP 112 \\
\hline 0.025 & 272 & 112 \\
\hline 0.1 & 272 & 112 \\
\hline 1 & 224 & 112 \\
\hline 10 & 224 & 112 \\
\hline $10^{2}$ & 232 & 116 \\
\hline $10^{3}$ & 272 & 112 \\
\hline $10^{4}$ & 280 & 120 \\
\hline $10^{5}$ & 46.0 & 16.0 \\
\hline $5 \times 10^{5}$ & 10.8 & 6.40 \\
\hline $10^{6}$ & 7.6 & 3.88 \\
\hline $5 \times 10^{6}$ & 6.4 & 3.88 \\
\hline $10^{7}$ & 6.8 & 3.20 \\
\hline $1.4 \times 10^{7}$ & 4.8 & 2.72 \\
\hline
\end{tabular}

\begin{tabular}{|l|l|l|l|l|l|l|}
\hline $\begin{array}{l}\text { Name } \\
\text { of } \\
\text { Sample }\end{array}$ & $\begin{array}{l}\text { Start to } \\
\text { mount }\end{array}$ & $\begin{array}{l}\text { Stop to } \\
\text { mount }\end{array}$ & Total & $\begin{array}{l}\text { Time } \\
\text { mesuarments } \\
\text { (s) }\end{array}$ & $\begin{array}{l}\text { Flux of } \\
\text { neutron }\end{array}$ & $\begin{array}{l}\text { Dose } \\
\text { rate } \\
\text { mSv/h }\end{array}$ \\
\hline Au-Lx5 & $\begin{array}{l}04 / 23 / 14 \\
08: 00: 00\end{array}$ & $\begin{array}{l}04 / 23 / 14 \\
08: 20: 00\end{array}$ & 1200 & 37782 & 15,153 & 1.39 \\
\hline Au- Lx6 & $\begin{array}{l}04 / 23 / 14 \\
08: 00: 00\end{array}$ & $\begin{array}{l}04 / 23 / 14 \\
08: 20: 00\end{array}$ & 1200 & 7036 & 23,524 & 2.16 \\
\hline Au-Lx7 & $\begin{array}{l}04 / 23 / 14 \\
08: 00: 00\end{array}$ & $\begin{array}{l}04 / 23 / 14 \\
08: 20: 00\end{array}$ & 1200 & 8801 & 7,795 & 0.72 \\
\hline Au- VN5 & $\begin{array}{l}04 / 23 / 14 \\
08: 00: 00\end{array}$ & $\begin{array}{l}04 / 23 / 14 \\
08: 20: 00\end{array}$ & 1200 & 11803 & 10,603 & 0.97 \\
\hline Au-Lx1 & $\begin{array}{l}04 / 23 / 14 \\
08: 00: 00\end{array}$ & $\begin{array}{l}04 / 23 / 14 \\
08: 20: 00\end{array}$ & 1200 & 8159 & 5,210 & 0.48 \\
\hline Au-Lx2 & $\begin{array}{l}04 / 23 / 14 \\
08: 00: 00\end{array}$ & $\begin{array}{l}04 / 23 / 14 \\
08: 20: 00\end{array}$ & 1200 & 2370 & 8,485 & 0.78 \\
\hline Au Lx3 & $\begin{array}{l}04 / 23 / 14 \\
08: 00: 00\end{array}$ & $\begin{array}{l}04 / 23 / 14 \\
08: 20: 00\end{array}$ & 1200 & 8201 & 6,335 & 0.58 \\
\hline Au- Lx4 & $\begin{array}{l}04 / 23 / 14 \\
08: 00: 00\end{array}$ & $\begin{array}{l}04 / 23 / 14 \\
08: 20: 00\end{array}$ & 1200 & 3392 & 5,295 & 0.49 \\
\hline
\end{tabular}

Table 4: Neutron dose rate in positions of the radiation therapy room.

Weigh Radiation of neutron very high, so it damages for tissue of patients. And it contribute to total of dose. Therefore, to ensure safety during and after the treatment we recommend:

- There are specific calculations of dose distributions produce neutrons in radiotherapy rooms with great projects and conduct done with most of the hospitals. 
Citation: Hai NV, Hung NV, Hoa NV, Nhung DTK (2015) Investigation of Neutron in Linear Accelerator at Dong Nai Genegal Hospital by Using the Neutron Activation Method. J Nucl Med Radiat Ther 6: 222. doi:10.4172/2155-9619.1000222

Page 4 of 4

- On the basis of these research results, we must to conculate for shielding to ensure the safety of patients. It will be to make important basis to cater for the old hospital and new hospital.

\section{References}

1. Ngo Quang Huy (2006) Base on nuclear physics. Science and Technical publish.

2. http://www.unimasr.net/ums/upload/files/2011/Dec/ UniMasr.com_c2ee784814d50b7354a490bce4424a6d.pdf.

3. [No authors listed] (1999) Radiation Protection Distance Learning. Australian Nuclear Science \& technology Organization. Sydney, Australia.
4. Herman Center (1996) "Introduction to health Physics". The McGraw Hill Copmanies, Inc.

5. Lin SY, Chu TC, Lin JP (2001) Monte Carlo simulation of a clinical linear accelerator. Appl Radiat Isot 55: 759-765.

6. Omrane LB Verhaegen F, Chahed N, Mtimet S (2003) An investigation of entrance surface dose calculations for diagnostic radiology using Monte Carlo simulations and radiotherapy dosimetry formalisms. Physics in Medicine and Biology 48: 1809-1824. 